\title{
QUALIDADE E IDENTIDADE DE EMBUTIDOS PRODUZIDOS NO BAIXO VALE DO RIO DO PEIXE, SANTA CATARINA - BRASIL
}

\author{
QUALITY AND IDENTITY OF FERMENTED SALAMI-TYPE SAUSAGES \\ PRODUCED IN THE BAIXO VALE OF RIO DO PEIXE, SANTA CATARINA - \\ $B R A Z I L$
}

Fabiano Pasqual D’Agostini

Serviço Nacional de Aprendizagem Industrial (SENAI/SC), E-mail: dagostini@sc.senai.br

\section{Poliana Campana}

Serviço Nacional de Aprendizagem Industrial (SENAI/SC), E-mail: polianac@sc.senai.br

\section{Roberto Degenhardt}

Serviço Nacional de Aprendizagem Industrial (SENAI/SC), E-mail: robertod@sc.senai.br

Resumo: a preocupação com a qualidade dos alimentos e com o número de fraudes aos quais estão relacionados é crescente. Em virtude desta preocupação e a ideia de que os produtos industrializados são prejudiciais à saúde humana, a busca por alimentos artesanais tem sido um incentivo às pequenas agroindústrias que possuem maior condição operacional para este tipo de fabricação. Vale ressaltar que a produção de embutidos coloniais é tradicional no Vale do Rio do Peixe (SC), sendo que sempre foi presente deste o início de sua colonização. O objetivo deste trabalho foi avaliar as características físico-sensoriais, físico-químicas e microbiológicas de embutidos coloniais produzidos por pequenas e médias agroindústrias da região do baixo Vale, buscando seu padrão de identidade e adequação à legislação. Foram analisadas trinta amostras de seis diferentes estabelecimentos e observou-se a manutenção de características físicas e sensoriais que foram consideradas típicas de produtos coloniais. Concluiu-se que é uma tendência na região a comercialização e consumo destes produtos com atividade água mais alta, que o teor de proteína é maior e de gordura menor, do que os fixados pela legislação, e que embora a atividade água destes produtos seja maior do que a fixada pela legislação, a qualidade microbiológica é satisfatória.

Palavras chave: Embutidos cárneos; Qualidade de alimentos; Contaminação de alimentos; Salames; Linguiças coloniais. 
Abstract: the concern about food quality and with the number of frauds connected to it is growing. Because of this concern and of the idea that industrially processed foods are dangerous to human health, the search for craft-made foods has been an incentive to small agro-industries which have higher operating condition for this type of manufacturing. It is noteworthy that the production of fermented salami-type sausage is traditional in Vale do Rio do Peixe (SC), and has always been present since the beginning of its colonization. The objective of this study was to evaluate the physical-sensorial, physical-chemical and microbiological characteristics of salami-type sausage produced by small and medium agro-industries of the lower Vale, analysing their standard of identity and compliance with legislation. Thirty samples from six different establishments were analysed and the observance of physical and sensory characteristics that were considered typical of colonial products was observed. It was concluded that there is a local trend in the marketing and consumption of these products with higher water activity, that the protein content is higher and the fat content is lower than those set by legislation standards, and that although the water activity of these products is greater than the one fixed by legislation standards, the microbiological quality is satisfactory.

Keywords: Fermented salami-type sausage; Food quality; Food contamination; Salami. 


\section{INTRODUÇÃO}

O termo qualidade é definido como o conjunto de características que definem o valor comercial do produto e que permite sua classificação. Quando se trata de alimentos, a definição é ampliada, pois não envolve apenas atributos comerciais como também os relacionados aos aspectos nutricionais e sanitários. (MILLER, 1992; RIEDEL, 2005).

A produção caseira de salames iniciada por imigrantes italianos, no início do século vinte, foi o passo inicial para a produção destes no Brasil. Atualmente, a produção deste tipo de produto é bastante variada em função de diferenças de composição, calibre dos envoltórios, tamanho dos pedaços de carne e gordura, especiarias, utilização de processos de defumação e do período de maturação do produto antes de sua comercialização. (SPRICIGO e PIANOVSKY, 2005; CACCIOPPOLI et al., 2006).

O oeste catarinense tem na agroindústria uma de suas das principais bases econômicas. A produção caseira de embutidos, que anteriormente foi uma alternativa de sobrevivência para as famílias de agricultores, se profissionalizou e deu origem a empresas de grande, médio e pequeno porte. Contudo, a arte de produção de salames ainda é mantida pelos pequenos estabelecimentos que utilizam formulações passadas de geração a geração.

Grande parte dos trabalhos realizados no Brasil sobre a qualidade de salames foi desenvolvida na região Sul do país, focando, principalmente, a produção artesanal ou colonial, e os aspectos sanitários dos mesmos. (PEREIRA, 2004).

Os padrões de identidade de salames e linguiças coloniais produzidos no Brasil são fixados na Instrução Normativa (IN) $n^{\circ} 22$ (BRASIL, 2000), no entanto estas características são abordadas de forma ampla abrangendo a produção de embutidos num âmbito nacional.

Este trabalho busca registrar os aspectos físico-sensoriais, físico-químicos e microbiológicos dos embutidos curados e fermentados produzidos na região do Baixo Vale do Rio do Peixe, localizado no Meio Oeste do Estado de Santa Catarina, Brasil.

\section{MATERIAL E MÉTODOS}

\subsection{Amostragem}

Foram coletadas cinco amostras de um mesmo lote de seis estabelecimentos com inspeção estadual, de pequeno e médio porte, localizados em municípios do Baixo Vale do Rio do Peixe, no estado de Santa Catarina, no período de novembro a dezembro de 2008. Os estabelecimentos foram codificados com as letras " $A$ " a " $F$ ", a fim de se preservar sua identidade. Vale destacar que há 29 estabelecimentos registrados no Serviço Estadual de Inspeção (SANTA CATARINA, 2007), contudo apenas seis aderiram voluntariamente a este projeto. 


\subsection{Análise Física e Sensorial}

As características físicas das amostras foram avaliadas quanto ao peso individual das peças, medidas do calibre da tripa (extremidades e centro) e comprimento. A cor externa foi avaliada através da escala japonesa de medida de cor (ANTUNES, 2006). Avaliou-se a presença de aromas de fumaça e o tipo de envoltório utilizado.

\subsection{Análise Físico-química}

A composição centesimal dos salames foi determinada através de metodologias oficiais do Ministério da Agricultura, Pecuária e Abastecimento (BRASIL, 1999). Também foram determinados os padrões de qualidade relativos ao teor de sal pelo método mercurométrico (BRASIL, 1999), pH com potenciômetro QUIMIS e atividade água através do ponto de orvalho, empregando-se o equipamento Medidor de Multi-parâmetros TESTO 650.

\subsection{Análise Microbiológica}

Determinaram-se as contagens de Escherichia coli por plaqueamento em profundidade com o meio Violeta Vermelho Bile com MUG (ACUMEDIA cod.7359) incubado a $36^{\circ} \mathrm{C} / 18$-24h; Staphylococcus aureus com plaqueamento em superfície no Agar Baird Parker (MERCK cód. 1.05406) incubado a $36^{\circ} \mathrm{C} / 24-48 \mathrm{~h}$ e Clostrídios Sulfito Redutores por plaqueamento em profundidade com sobre camada empregando o Agar Sulfato de Polimixina Sulfadiazina incubados a $35^{\circ} \mathrm{C} / 24-48 \mathrm{~h}$ (MERCK cód. 1.10235) (SILVA, 1997). A pesquisa de presença de Salmonella foi realizada através do método ISO 6579:2002/ Amd.1:2007, empregando o meio semi-sólido Rappaport-Vassiliadis MSRV (ACUMEDIA cód. 7511) (ISO, 2007) e a pesquisa de Listeria monocytogenes através do método ISO 11290-1:1996/Amd.1:2004, empregando o agar OTTAVIANI e AGOSTI-ALOA (LABORCLIN cód. 911049) como meio de isolamento (ISO, 2004). As contagens de bactérias ácidolácticas foram realizadas com Agar de Man, Rogosa e Sharpe (ACUMEDIA, 7543) incubado em microaerofilia a $30^{\circ} \mathrm{C} / 72 \mathrm{~h}$ (ISO, 1998).

\subsection{Análise Estatística}

Os resultados foram tratados empregando-se a análise de variância (ANOVA) para avaliar a existência de diferenças significativas ao nível de $5 \%$. 


\section{RESULTADOS E DISCUSSÃO}

A análise das amostras, sob a ótica dos parâmetros físico-sensoriais foi iniciada pela avaliação das características físico-sensoriais e do rótulo. Com relação à denominação de venda os produtores " $A$ ", "E" e " $F$ " descrevem o produto como "Salame Tipo Italiano", o produtor "B" como "Salame Colonial Defumado", o produtor "C" como "Salame tipo Colonial" e o produtor " $\mathrm{D}$ " como "Linguiça tipo Colonial". Embora a Linguiça tipo Colonial seja um produto diferente do Salame, o estudo também contemplou este tipo de produto porque a tecnologia de produção empregada na região não é significativamente diferente, e o consumidor local também não faz esta distinção. Tomando-se por base as descrições dos padrões de identidade e qualidade para os embutidos fermentados fixados pela Instrução Normativa 22 (BRASIL, 2000) a terminologia "Salame Tipo Colonial" não é oficial.

Priorizou-se a coleta de amostras com o menor tempo de vida de prateleira entre a produção e análise, sendo a amostra " $D$ ", a que tinha maior tempo de validade transcorrido (14 dias). As amostras " $A$ ", " $B$ " e " $F$ " foram analisadas dois dias após a produção, a amostra "E" após seis dias e a " $C$ " nove dias após a produção. Este dado é importante na avaliação, pois os embutidos fermentados produzidos nesta região são produtos dinâmicos que continuam o processo de maturação (secagem) ao longo da vida de prateleira, apresentando uma grande variação dos parâmetros físico-químicos e, por consequência, microbiológicos.

Com relação ao tempo de validade também foram observadas variações entre 60 dias (produtores " $A$ ", " $C$ " e " $F$ ") e 90 dias (produtores "B" e "E"). O produtor "D" estipula um prazo de validade de 75 dias.

A Tabela 1 apresenta as principais características físicas das amostras avaliadas. Observouse que é uma característica dos produtores da região o uso de envoltórios naturais. A cor mensurada pela escala japonesa de cores de carne variou consideravelmente do nível 2 (característica de carne fresca) até o nível 6 (cor da carne curada), sendo que a maioria das amostras possuía a característica de curada (vermelho vivo). Apenas a amostra 6 apresentava características de início de cura (cor rósea), que na região é denominado "salame verde". A forma de apresentação dos produtos foi condizente com as características esperadas para salames (formato linear) e para linguiça colonial (forma de ferradura). 
Tabela 1 - Características Físico-sensoriais de embutidos fermentados produzidos no Baixo Vale do Rio do Peixe, SC - Brasil

\begin{tabular}{|c|c|c|c|c|c|c|c|c|c|}
\hline \multirow{2}{*}{ Produtor } & \multicolumn{2}{|c|}{ Apresentação } & \multicolumn{2}{|c|}{ Peso (g) } & \multicolumn{2}{|c|}{ Comprimento $(\mathrm{cm})$} & \multicolumn{2}{|c|}{ Calibre (mm) } & \multirow{2}{*}{$\operatorname{Cor}(*)$} \\
\hline & Forma & Envoltório & Média & DP & Média & DP & Média & DP & \\
\hline A & Linear & Natural & 397 & 34,2 & 30,00 & 0,80 & 44 & 2 & $4 / 3$ \\
\hline B & Linear & tural & 331 & 30,1 & 30,10 & 1,3 & 41 & 2 & $5 / 4$ \\
\hline C & Linear & Artificial & 314 & 7,4 & 22,70 & 0,50 & 47 & 1 & $6 / 5$ \\
\hline D & Ferradura & Natural & 444 & 47,6 & 41,90 & 3,10 & 43 & 3 & $5 / 4$ \\
\hline E & Linear & Natural & 200 & 47,1 & 21,00 & 1,00 & 38 & 4 & 6 \\
\hline $\mathrm{F}$ & Linear & Natural & 305 & 21,5 & 25,50 & 1,40 & 41 & 3 & $3 / 2$ \\
\hline
\end{tabular}

DP: desvio padrão; $\left({ }^{*}\right)$ Classificação da cor segundo a escala japonesa de cores da carne.

Em se tratando dos Parâmetros Físico Químicos, os resultados referentes à composição centesimal (Tabela 2) demonstraram que entre os produtores há pouca semelhança dos produtos, devendo-se estas variações, principalmente, as variações de formulação e parâmetros de fermentação e maturação do produto.

Tabela 2 - Resultados de análises físico-químicas de produtos cárneos embutidos e fermentados produzidos no Baixo Vale do Rio do Peixe, SC

\begin{tabular}{|c|c|c|c|c|c|c|c|}
\hline \multirow{2}{*}{\multicolumn{2}{|c|}{ Determinações }} & \multicolumn{6}{|c|}{ Produtor e Resultados } \\
\hline & & \multirow{2}{*}{$\begin{array}{c}A \\
23,50\end{array}$} & \multirow{2}{*}{$\begin{array}{c}\text { B } \\
17,98\end{array}$} & \multirow{2}{*}{$\begin{array}{c}C \\
21,22\end{array}$} & \multirow{2}{*}{$\begin{array}{c}D \\
12,02\end{array}$} & \multirow{2}{*}{$\begin{array}{c}E \\
15,87\end{array}$} & \multirow{2}{*}{$\begin{array}{c}F \\
18,35\end{array}$} \\
\hline \multirow{3}{*}{ Gordura (\%) } & Média & & & & & & \\
\hline & DP & 2,08 & 0,82 & 0,37 & 0,90 & 2,44 & 0,66 \\
\hline & CV (\%) & 8,83 & 4,54 & 1,76 & 7,45 & 15,34 & 3,61 \\
\hline \multirow{3}{*}{ Proteína (\%) } & Média & 20,16 & 26,75 & 24,20 & 23,70 & 33,78 & 19,99 \\
\hline & DP & 0,57 & 0,77 & 1,25 & 1,17 & 2,39 & 0,94 \\
\hline & CV (\%) & 2,80 & 2,87 & 5,16 & 4,93 & 7,08 & 4,71 \\
\hline \multirow{3}{*}{ Umidade (\%) } & Média & 51,75 & 49,71 & 49,94 & 59,42 & 43,32 & 58,24 \\
\hline & DP & 2,01 & 1,12 & 1,38 & 1,60 & 2,52 & 1,58 \\
\hline & CV (\%) & 3,88 & 2,26 & 2,76 & 2,69 & 5,82 & 2,71 \\
\hline \multirow{3}{*}{ Aw } & Média & 0,933 & 0,937 & 0,922 & 0,945 & 0,865 & 0,952 \\
\hline & DP & 0,018 & 0,004 & 0,017 & 0,004 & 0,018 & 0,004 \\
\hline & CV (\%) & 1,88 & 0,41 & 1,87 & 0,39 & 2,11 & 0,40 \\
\hline \multirow{3}{*}{$\mathrm{NaCl}(\%)$} & Média & 3,79 & 4,46 & 4,46 & 4,72 & 5,57 & 2,49 \\
\hline & DP & 0,11 & 0,05 & 0,51 & 0,25 & 0,41 & 0,08 \\
\hline & CV (\%) & 2,84 & 1,12 & 11,54 & 5,39 & 7,34 & 3,12 \\
\hline \multirow{3}{*}{$\mathrm{pH}$} & Média & 4,94 & 5,50 & 5,19 & 6,00 & 5,30 & 5,24 \\
\hline & DP & 0,05 & 0,04 & 0,06 & 0,10 & 0,17 & 0,03 \\
\hline & CV (\%) & 1,05 & 0,68 & 1,18 & 1,74 & 3,15 & 0,64 \\
\hline
\end{tabular}

DP: Desvio padrão; CV (\%): Coeficiente de variação em percentual. 
Observou-se que o padrão de gordura observado identificado nos produtos dos diferentes estabelecimentos ficou bem abaixo dos valores determinados pelos requisitos legais (máximo de $35 \%$ em salames e $30 \%$ em linguiças). A homogeneidade tanto dentro dos lotes como entre os estabelecimentos variou consideravelmente, com exceção dos estabelecimentos $B, E$ e F, que não apresentaram diferenças significativas entre os lotes avaliados.

Os resultados das análises de proteína demonstraram que quatro produtores atendem aos requisitos legais fixados na IN 22, e dois, os estabelecimentos $A$ e $F$, estão em inconformidade como o limite mínimo de $20 \%$. O estabelecimento A apresenta um resultado médio dentro do padrão, mas a dispersão dos resultados dentro do lote indica $60 \%$ das amostras abaixo do limite legal. $\mathrm{O}$ estabelecimento $\mathrm{F}$ não atingiu o valor médio equivalente ao padrão legal e apresenta como o produtor $A$, a mesma dispersão dentro do lote, confirmado pela análise estatística ( $F=0,126 ; F$ crítico 5,318$)$. Os resultados das análises dos lotes do estabelecimento $D$ e $C$ também não apresentaram diferença estatística ao nível de $5 \%$. O lote de linguiça colonial também se apresentou dentro do limite legal de no mínimo $18 \%$ de proteína, específico para linguiça colonial. O fator que determina se o salame está pronto para o consumo, ou seja, a fermentação e maturação concluídas, e apto à comercialização, é o teor de umidade. Nesta avaliação, nenhum dos produtores que definiram seus produtos como salame, atenderam à legislação, que fixa um teor máximo de $40 \%$ de umidade. Não existe um teor mínimo de umidade fixado para a linguiça colonial na IN 22, mas se os resultados da análise da linguiça colonial forem confrontados com a IN $n^{\circ} 4$ de 31/03/2000, que fixa o teor máximo de $55 \%$ de umidade para as linguiças dessecadas, o estabelecimento também apresenta a não conformidade. Os valores de umidade são importantes nesta classe de produtos, pois determinam a viabilidade de multiplicação e sobrevivência de diversos micro-organismos patogênicos e deteriorantes devido a alta atividade água $\left(A_{w}\right)$ que o produto pode apresentar.

Dentre os estabelecimentos avaliados, apenas o $\mathrm{E}$ apresentou o lote analisado com valor de atividade água condizente com a legislação. Os demais lotes apresentaram $A_{w}$ acima dos prescritos pela legislação. Dados similares são descritos por Degenhardt e Sant'Anna (2007). Este panorama demonstra que os salames são comercializados antes da maturação ser completada. A análise estatística demonstrou a similaridade dos lotes dos estabelecimentos $A, B, C$, e $D$, sendo os três primeiros salames com maturação incompleta. Deve-se ressaltar que a $A_{w}$ das linguiças coloniais (estabelecimento $D$ ) é mais alta do que dos salames pelo motivo de possuírem um conteúdo de água maior.

Os teores de sal também variaram entre os estabelecimentos e, em parte, deve-se ao grau de dessecação que o produto apresenta, quanto mais seco, maior o teor de sal. $O$ lote do estabelecimento $E$ apresentou a maior quantidade de sal (em média 5,57\%) devido ser o que apresentou a menor umidade e mais baixa atividade água. Os resultados obtidos aproximam-se dos obtidos por Degenhardt e Sant'Anna (2007). 
$\mathrm{O}$ pH é o indicador da intensidade de fermentação que os produtos sofreram, e com base nos dados obtidos, verifica-se que a fermentação é um fator pouco observado devido as grandes variações obtidas entre os diversos estabelecimentos avaliados. Parte dos resultados elevados podem ser atribuídos ao pouco tempo que os produtos permanecem sob as condições que permitem que estas reações aconteçam, e ao não uso de culturas comerciais padronizadas para a condução desse processo. Verifica-se, portanto, que a fermentação nestes casos é um processo espontâneo.

Sob a verificação dos parâmetros microbiológicos, a fermentação no processo de fabricação de salames é atribuída à presença de bactérias ácido-lácticas. Nas amostras avaliadas não se observou diferenças significativas nas contagens destes microorganismos entre os seis lotes analisados, já as contagens oscilaram entre 7,0 log UFC/g e $8,0 \log$ UFC/g.

Não foram detectadas a presença de Salmonella e, tampouco, de Listeria monocytogenes nos lotes avaliados. Com relação à presença de outras espécies de Listeria, foram detectadas nos lotes provenientes dos estabelecimentos C, D, E e F.

Com relação aos demais patógenos (Tabela 3) verificou-se que o lote de embutidos proveniente do estabelecimento $F$ apresentou condições sanitárias insatisfatórias segundo a Resolução 12 da ANVISA com relação às contagens de Escherichia coli e Staphylococcus aureus. Ressalta-se que as contagens de $S$. aureus ainda são insuficientes para a produção de enterotoxina, que apenas em contagens de 7 log UFC são representativas (JAY, 2005). Os demais lotes apresentam contagens que os classificam como "Produtos em condições satisfatórias para consumo".

No levantamento semelhante realizado por Lobo et al. (2001), em Santa Maria (RS) verificou-se que $66,67 \%$ das amostras $(n=60)$ eram impróprias para consumo e que em $65 \%$ das amostras a contagem de S. aureus foi maior ou igual a $6 \mathrm{log}$ UFC/g. Magnani et al. (2000) avaliaram 50 amostras de salames coloniais procedentes de Chapecó (SC) e verificaram $6 \%$ de contaminação por Salmonella e $84 \%$ por Escherichia coli. Ritter et al. (2003) realizaram um estudo no Rio Grande do Sul, com treze amostras de embutidos coloniais e observaram a presença de coliformes fecais em mais de $50 \%$ das amostras e contagens de S. aureus da ordem de 5 log UFC/g. Hoffman et al. (1997) detectaram Salmonella em $25 \%$ das amostras avaliadas e em outros $25 \%$ as contagens de $S$. aureus foram da ordem de 4 log UFC/g. 
Tabela 3 - Resultados de análises microbiológicas $\left(\log \mathrm{g}^{-1}\right)$ de produtos cárneos embutidos e fermentados produzidos no Baixo Vale do Rio do Peixe, SC.

\begin{tabular}{|c|c|c|c|c|c|c|c|c|}
\hline \multirow{2}{*}{ Determinações } & \multirow{2}{*}{ Amostra } & \multirow{2}{*}{ RDC 12} & \multicolumn{6}{|c|}{ Estabelecimentos e Resultados $\left(\log g^{-1}\right)$} \\
\hline & & & A & B & C & D & E & $\mathbf{F}$ \\
\hline \multirow{5}{*}{$\begin{array}{c}\text { Escherichia coli/ } \\
\text { UFC g }\end{array}$} & 1 & $n=5$ & $<1,0$ & 1,30 & $<1,0$ & 1,70 & $<1,0$ & 3,62 \\
\hline & 2 & $c=2$ & $<1,0$ & 1,00 & $<1,0$ & $<1,0$ & 1,85 & 1,00 \\
\hline & 3 & $m=2,0 \log$ & $<1,0$ & $<1,0$ & $<1,0$ & $<1,0$ & 1,48 & 3,23 \\
\hline & 4 & $M=3,0 \log$ & $<1,0$ & $<1,0$ & $<1,0$ & $<1,0$ & $<1,0$ & 1,00 \\
\hline & 5 & & $<1,0$ & 2,36 & $<1,0$ & 1,48 & 1,00 & 3,99 \\
\hline \multirow{5}{*}{$\begin{array}{l}\text { Staphylococcus } \\
\text { aureus UFC g }{ }^{-1}\end{array}$} & 1 & $n=5$ & $<2,00$ & $<2,00$ & 2,48 & $<2,00$ & $<2,00$ & 4,78 \\
\hline & 2 & $c=1$ & $<2,00$ & $<2,00$ & 2,00 & $<2,00$ & 2,00 & 4,30 \\
\hline & 3 & $m=3,0 \log$ & $<2,00$ & $<2,00$ & $<2,00$ & 2,30 & $<2,00$ & 4,90 \\
\hline & 4 & $M=3,7 \log$ & $<2,00$ & 2,00 & 2,00 & $<2,00$ & $<2,00$ & 4,70 \\
\hline & 5 & & $<2,00$ & $<2,00$ & 3,30 & $<2,00$ & $<2,00$ & 3,00 \\
\hline \multirow{5}{*}{$\begin{array}{l}\text { Clostrídios Sulfito } \\
\text { Redutores UFC g-1 }\end{array}$} & 1 & \multirow{5}{*}{ não há } & $<1,0$ & $<1,0$ & $<1,0$ & $<1,0$ & $<1,0$ & 1,00 \\
\hline & 2 & & $<1,0$ & $<1,0$ & $<1,0$ & 1,00 & $<1,0$ & $<1,0$ \\
\hline & 3 & & $<1,0$ & $<1,0$ & $<1,0$ & $<1,0$ & $<1,0$ & $<1,0$ \\
\hline & 4 & & $<1,0$ & $<1,0$ & $<1,0$ & 1,30 & $<1,0$ & $<1,0$ \\
\hline & 5 & & $<1,0$ & $<1,0$ & $<1,0$ & 1,70 & $<1,0$ & $<1,0$ \\
\hline
\end{tabular}

RDC 12: Resolução $n^{\circ} 12$ de 02/01/2001. $n$ : número de unidades a serem colhidas aleatoriamente de um mesmo lote e analisadas individualmente. $c$ : número máximo aceitável de unidades de amostras com contagens entre os limites " $\mathrm{m}$ " $\mathrm{e}$ " $\mathrm{M}$ " (planos de três classes). $m$ : limite que, em um plano de três classes, separa o lote aceitável do produto ou lote com qualidade intermediária aceitável. M: limite que em um plano de duas três classes, separa o lote com qualidade intermediária aceitável do lote inaceitável. Valores acima de $M$ são inaceitáveis. (BRASIL, 2001).

\section{CONCLUSÕES}

A avaliação das características físico-sensoriais permite concluir que os produtos embutidos fermentados produzidos na região apresentam características típicas de produtos artesanais, como o uso de envoltórios naturais e a defumação. O hábito do consumo do produto "verde", ou seja, com a maturação incompleta pode ser verificado na maioria dos lotes avaliados, o que pode ser considerado como uma fraude e um sério risco a saúde dos consumidores destes alimentos.

Os parâmetros físico-químicos demonstram que, em geral, os produtos da região têm um apropriado valor em proteínas e se caracterizam pelo baixo teor de gorduras, o que é salutar para o consumidor.

De uma maneira geral e levando-se em consideração os valores de atividade água frente às características microbiológicas, verificaram-se boas condições sanitárias dos produtos avaliados quando comparados aos parâmetros determinados pela legislação. Quando se compara os resultados obtidos neste trabalho com trabalhos semelhantes realizados nos estados de Santa Catarina e Rio Grande do Sul, também se observa uma qualidade satisfatória. 


\section{REFERÊNCIAS}

ANTUNES, R. C. O futuro da qualidade de carne no Brasil e a pesquisa com qualidade. Porkworld, São Paulo, n. 32, mai./jun. 2006. Disponível em: < http://www.dalland.com. br/biblioteca/artigos/200605sd.htm>. Acesso em: 12 out. 2008.

BRASIL. Ministério da Agricultura e do Abastecimento. Instrução Normativa $n^{\circ} 20$, que oficializa os Métodos Analíticos Físico-químicos, para controle dos produtos cárneos e seus ingredientes - Sal e Salmoura. Diário Oficial da União, Brasília, DF, 27 jul. 1999. Seção 1, p. 10.

BRASIL. Ministério da Agricultura e do Abastecimento. Regulamentos Técnicos de Identidade e Qualidade de Carne Mecanicamente Separada, de Mortadela, de Lingüiça e de Salsicha - Instrução Normativa n. 4, de 31 de março de 2000. Diário Oficial da União, Brasília, DF, 05. abr. 2000. Seção 1, p. 6.

BRASIL. Ministério da Agricultura e do Abastecimento. Regulamentos técnicos de identidade e qualidade de Copa, de Jerked Beef, de Presunto tipo Parma, de Presunto Cru, de Salame, de Salaminho, de Salame tipo Alemão, de Salame tipo Calabrês, de Salame tipo Friolano, de Salame tipo Napolitano, de Salame tipo Hamburguês, de Salame tipo Italiano, de Salame tipo Milano, de Linguiça Colonial e Pepperoni Instrução Normativa n. 22, de 31 julho de 2000. Diário Oficial da União, Brasília, DF, 03 ago. 2000. Seção 1, p. 15.

BRASIL. Ministério da Saúde. Agência Nacional de Vigilância Sanitária. Regulamento técnico sobre padrões microbiológicos para alimentos - RDC 12 de 02 de janeiro de 2001. Diário Oficial da União, Brasília, DF, 10 jan. 2001.

CACCIOPPOLI, J. et al. Aminas bioativas e características físico-químicas de salames tipo italiano. Arq. Bras. Med. Vet. Zootec., Belo Horizonte, v.58, n.4, p.648-657, 2006.

DEGENHARDT, R; SANT'ANNA, E.S. Pesquisa de Listeria sp em embutidos cárneos fermentados produzidos na região Meio-Oeste de Santa Catarina, Brasil. Boletim CEPPA, Paraná, v. 25, n. 1, p. 133-140, 2007.

HOFFMANN L. F. et al. Estudo higiênico-sanitário preliminar de amostras de salame. Higiene Alimentar, São Paulo, v. 11, n. 47, p. 42 - 44, 1997. 
ISO 15214:1998 (E). Microbiology of food and animal feeding stuffs. Horizontal method for the enumeration of mesophilic lactic acid bacteria. Colony-count technique at $30^{\circ} \mathrm{C}$. Geneva: International Standard Organization, 1998. 8 p.

ISO 11290-1:1996/Amd.1:2004 (E). Microbiology of food and animal feeding stuffs. Horizontal method for the detection and enumeration of Listeria monocytogenes. Part 1: Detection method. AMENDMENT 1: Modification of the isolation media and haemolysis test, and inclusion of precision data. Geneva: International Standard Organization, 2004. 13 p.

ISO 6579:2002/Amd. 1:2007(E). Microbiology of food and animal feeding stuffs. Horizontal method fordetection of Salmonella spp. AMENDMENT 1: Annex D: Detection of Salmonella spp. in animal faeces and in environmental samples from primary production stage. Geneve: International Standard Organization, 2007. 9 p.

JAY, J.M. Microbiologia de alimentos. 6. ed. Porto Alegre: ARTMED, 2005. 711 p.

LOBO, V. M. et al. Avaliação microbiológica de salames coloniais comercializados no município de Santa Maria - RS. Higiene Alimentar, São Paulo, v. 15, n. 88, p. 57-61, 2001.

MAGNANI, L. A., et al. Incidência de Salmonella e Escherichia coli em carne suína in natura e salame colonial, consumidos pela população de Chapecó - SC. Higiene Alimentar, São Paulo, v. 14, n. 73, p. $44-47,2000$.

MILLER, Sanford A. Novel foods: safety and nutrition. Food Technology. Chicago, v. 43, n. 3, p. 114-117, 1992.

PEREIRA, K. S. Patógenos bacterianos em salames. Revista Nacional da Carne, São Paulo, v. 28, n.328, 2004. Disponível em: <http://www.dipemar.com.br > . Acesso em: 26 jan. 2006.

RIEDEL, Guenther. Controle sanitário dos alimentos. São Paulo: Atheneu, 2005.

RITTER R., et al. Microbiologia contaminante e patogênica de linguiça (salame) colonial, analisada em quatro períodos distintos. Higiene Alimentar, São Paulo, v. 17, n. 113, p. 60-66, 2003. 
SANTA CATARINA (Estado). Secretaria do Estado da Agricultura e Desenvolvimento. Companhia integrada de desenvolvimento agrícola de Santa Catarina. Relação dos Estabelecimentos SIE. Disponível em: < http://200.19.216.26/Geral/relatorio/imprime. aspx?Relatorio=REL_ESTABELECIMENTOSIE >. Acesso em: 26 nov. 2007.

SILVA, N.; JUNQUEIRA, V.C.A.; SILVEIRA, N.F.A. Manual de métodos de análise microbiológica de alimentos. São Paulo: Varela, 1997. 295 p.

SPRICIGO, C.B.; PIANOVSKY, P.B. Effect of the use of curing salts and of a starter culture on the sensory and microbiological characteristics of homemade salamis. Brazilian Archives of Biology and Technology, v. 48, n. especial, p. 169-174, jun. 2005.

\section{AGRADECIMENTOS}

Ao programa Pró-Pesquisa do SENAI/SC que viabilizou os recursos necessários ao desenvolvimento deste trabalho. 


\section{SOBRE O AUTOR}
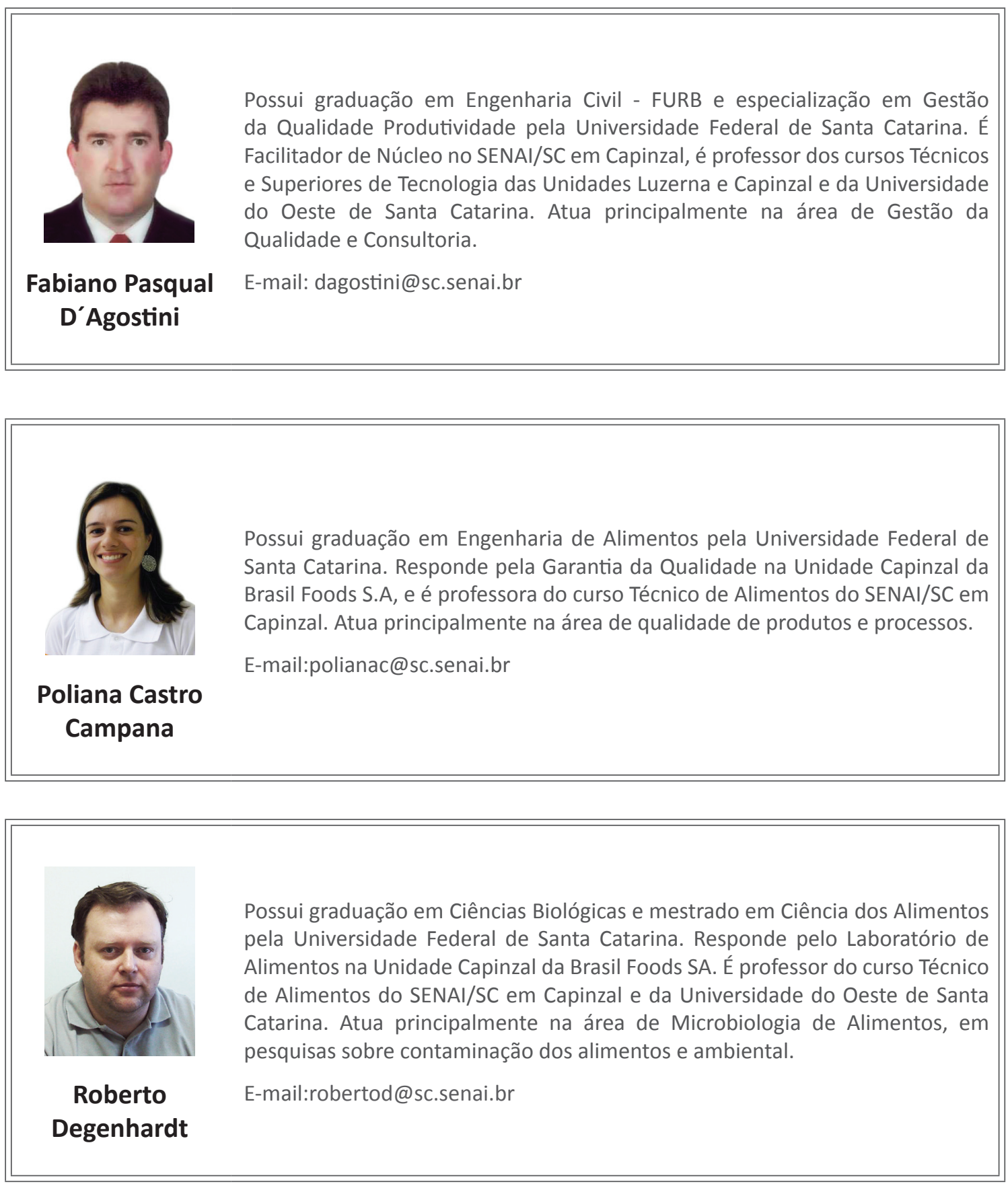